\title{
Investigating the Decision Heuristics of Candidate Teachers Who are Different in Their Responsibility Controls
}

\author{
Yener Özen \\ Department of Education Science, Faculty of Education, Erzincan University, Turkey
}

Copyright $(2016$ by authors, all rights reserved. Authors agree that this article remains permanently open access under the terms of the Creative Commons Attribution License 4.0 International License

\begin{abstract}
In this study, decision heuristics used by individuals with different responsibility controls were investigated. In the research, 370 final grade university students studying at Erzincan University Faculty of Education were included. In order to collect data, Internally Controlled Responsibility-Externally Controlled Responsibility Scale of Özen and Gülaçtı (2011), and Decision Heuristics Scale developed by Özen (2015) were used. Obtained data were investigated benefiting from Pearson Product-Moment Correlation and t-test. As result of the analyses, it was determined that the students generally had internally controlled responsibility, and they mostly used representative heuristic. When the correlation of decision heuristics with Internally Controlled Responsibility-Externally Controlled Responsibility was investigated, a low level negative relationship was found between representative heuristic and Internally Controlled Responsibility-Externally Controlled Responsibility. A low level positive relationship was found between availability and adjustment heuristics and Internally Controlled Responsibility-Externally Controlled Responsibility. In the research, moreover, it was also determined when the students who had internally controlled responsibility were compared with the ones who had externally controlled responsibility that the students with internally controlled responsibility significantly used more logical representative heuristic and less availability heuristic and anchoring heuristic.
\end{abstract}

Keywords Decision Heuristics, Internally Controlled Responsibility-externally Controlled Responsibility, Candidate Teachers

\section{Introduction}

In today's world when educational, social and political rapid change has been experienced, values, thinking ways and priorities of people have also been affected and changed.
This change shows its effect in all organizations, and affects these in terms of structure, strategy, and process. Within this changing environment, managers can encounter various problems while achieving their pre-determined purposes. The presence of these problems obliges them to find solutions, in other words, to make decisions. The quality and speed of the change the manager experiences, on the one hand, and the demand and necessity of fulfilling pre-determined purposes, on the other, cause the behavior of decision making [1]. In general terms, decision making is defined as making selection among the alternatives; if there is just one choice to be selected, then decision making is not possible to be mentioned [2]. When decision making is investigated as a concept, it is noticed to be defined in different ways. For instance, decision making was defined as a tending towards overcoming a problem experienced when there is more than one ways to a specific object that is considered to meet a requirement [3]. The concept of making decision is also defined as a) a decision, and any kind of judgment affecting the action; b) making selection among the alternatives in order for people to achieve the desired result; c) determining the sanction to be imposed for overcoming a problem; d) the process of judgment as result of assessments; e) the process of judging through interpreting or comparing the information related to an event or a problem. According to these definitions, decision making is the process of conclusion by making the most proper assessment among the alternatives. In this sense, decision making is a dynamic process, and individuals play an active role in this process [4].

Individuals acquire several experiences possible to be affected by several internal-external factors they developed previously during their decision making processes. These experiences create the decision making heuristics of individuals [5]. Heuristic is a cognitive process used for the solution of specific problems. The term is used to express a discipline discussing the discovery of events in sciences' system or method for providing students to find what is tried to be taught in education [6]. The term of heuristic in 
decision making indicates the ways of creating a number of answers that seem efficient but unconfirmed in their accuracy against the problems. These ways cause systematic bias when they are not efficient. In this sense, the concept of heuristic leads to bias [7]. Decision heuristics have also been used in Psychology. Especially when decision making is a matter of fact in uncertainty, heuristic refers to the cognitive process individuals use to overcome specific problems $[8,9$, $10,26]$. Within these processes, economy of effort is mostly employed, and simplifying strategies are followed. For example, all data or information is not regarded, individuals content with inadequate data, and all choices are not revised. Finally, few acceptable, but biased results are obtained [11].

Decision making heuristics are the pathway, shortcut of our mind. They let us make immediate decisions in uncertainties or problem solving processes. According to heuristics, judgments are created in accordance with the one that comes easy to mind and is encountered frequently. For example, if you and the people around you constantly have fast food, then the rate for you to make judgment on having fast food is high. What is much or frequent in your life is the one you think as much or frequent around you, and your reality judgment occurs according to this. Decision heuristics refer to thinking the fact that the objects resembling to each other have the similar characteristics. To sum up, it is making generalizations. Expecting the people of the same zodiac have the same personal traits, or thinking that everybody could deceit when one deceits you are the samples of basic heuristics. As mentioned by Nietzsche, all generalizations are wrong, including this one. The margin of error in these judgments as a shortcut is high. We cannot regard things as statistically little or much as we encounter them frequently in our life. When we see two people resembling to each other, our judging them to have the same characteristics can increase our inaccuracy rate. But it has the possibility of being correct; moreover, our life gets easier due to these heuristics, and we can make more immediate decisions. To sum up, heuristics are the pathways of our mind to make quick decisions, and they have margin of error as well as being correct [12].

According to Tversky [9], decision heuristics include representative, availability, adjustment and anchoring heuristics. Representative heuristic is the process of analyzing the choices carefully while making decisions, evaluating advantages and disadvantages of these choices, and making a decision in the end. In representative heuristic, it is remarkable to focus on a special quality disregarding the statistical information related to the elements of a category and to highlight the similarities. Representative heuristic means to decide by yourself without receiving help from the others. This one is used when determining something that will be in the future or that was in the past is possible. Availability heuristic is the type of extemporaneous decision-making by thinking adequately upon the choices. Here, making available factors to be prominent is essential instead of considering availability frequency of various factors within the whole. Anchoring heuristic is defined as desiring the decision according to any references, and looking constantly for other references dissatisfying with any decisions. It expresses to make judgment looking for a reference point in issues without any information. In another study, decision heuristics were investigated in four dimensions. These were internal knowledge heuristic, external knowledge heuristic, internal knowledge analyzing heuristic and external knowledge analyzing heuristic [13].

When the studies carried out upon decision heuristics were investigated, it was found that individuals' decision heuristic types varied depending upon various variables. For example, the variable of age was one of the variables creating difference in decision heuristic [14]. Attitude and approach of families was indicated as another significant variable for children's using decision heuristics [15]. Also decision heuristics in variables such as peer group pressure and self-respect were emphasized to have an effect upon behavior [16].

One of the variables affecting decision heuristics is individuals' having internal and external control locus. According to Rotter's Social Learning Theory, control locus is one of the most important corner stones of personality [17]. Control locus is individuals' level of accepting the individual responsibility as result of their own behaviors [18]. Internal responsibility is defined as individuals' accepting what they experience as result of their own behaviors, and external responsibility is defined as individuals' believing that what they experience is caused by fate, luck, fortune or the others. The individuals with internally controlled responsibility rather than the ones with externally controlled responsibility are noticed to take the responsibility of their own behaviors, work more to achieve the targets and be successful [19].

When the literature was revised, the relationship between responsibility control and decision heuristics was noticed to be investigated. For example, it was determined in a study that the individuals in mid and late adolescent period had more responsibility control and used more decision heuristics rather than the younger ones [17]. Also in other studies, it was specified that decision heuristics differed according to the individuals with internal and external decision heuristics. The individuals with external responsibility control tended to make decisions more dependent to the views of others rather than the ones with internal responsibility control [20]. These studies carried out in abroad proved a relationship between different responsibility control and decision heuristics. In Turkey, however, no study investigating the responsibility and decision heuristics was found.

For that reason, in this study, it was investigated whether university final grade students had internally controlled responsibility or externally controlled responsibility, or which decision heuristic they mainly used. It was also tried to be determined whether there was a significant difference between the decision heuristics used by the students who had internally controlled responsibility and externally controlled responsibility.

Determining the decision heuristics adapted by university 
final grade students during the stage of making important decisions such as post-graduate professional tendency (State School, Private School or Establishing their Own Business) and knowing which decision heuristics individuals with different responsibility controls used while making decisions during the decision-making process were essential in terms of planning the guidance and psychological counseling services to be rendered for them. If the students were determined to use decision heuristics inappropriate for them and they were individuals with externally controlled responsibility, then efficient decision making methods and logical, planned and programmed decision heuristics would be taught within the framework of guidance and psychological counseling services in educational institutions, and implementations related to developing personality traits of internally controlled responsibility would be included. So that appropriate studies and orientations in accordance with the interest and abilities of students could provide benefits in their accurate and appropriate professional tendency.

In accordance with this general purpose, answers to the questions below were sought in the research:

1. Which decision heuristics do the university students use?

2. Which responsibility control do the university students have?

3. Is there a significant relationship between responsibility control and decision heuristics?

4. Is there a significant difference between the decision heuristics used by the individuals with internally controlled responsibility and externally controlled responsibility?

\section{Methodology}

\subsection{Research Group}

Table 1. Distribution of the group participated in the research according to age, gender, and the school they study at

\begin{tabular}{|c|c|c|c|c|c|c|c|c|}
\hline Age & $\mathbf{n}$ & $\mathbf{\%}$ & Gender & $\mathbf{n}$ & $\mathbf{\%}$ & Faculty Type & $\mathbf{n}$ & $\mathbf{\%}$ \\
\hline 21 & 70 & 20 & Female & 185 & 50 & Sciences & 170 & 48.6 \\
\hline 22 & 184 & 46 & Male & 185 & 50 & Social & 200 & 51.5 \\
\hline 23 & 100 & 29 & Total & 370 & 100 & Total & 370 & 100 \\
\hline 24 & 17 & 5 & & & & & & \\
\hline Total & 370 & 100 & & & & & & \\
\hline
\end{tabular}

Totally 370 university final grade students studying at Erzincan University, Faculty of Education in province of Erzincan (Turkey) participated in the research. Age averages of the students was calculated as $22.24(\mathrm{SD}=1.86)$. Age distribution varied between 21 and 24 . In the research, $50 \%$ $(\mathrm{n}=185)$ of the students included female and $50 \%(\mathrm{n}=185)$ included male students. Also, $48.6 \%$ of the students that participated in the research studied at sciences and 51.5\% studied at social sciences. The information related to the demographical data was presented in Table 1.

\subsection{Data Collection Tools}

\subsubsection{Decision Heuristics Scale:}

In order to determine decision heuristics of the students, Decision Heuristics Scale developed by Özen [21]) was used. In the scale, the strategy of four decision heuristics as Representative Heuristic, Availability Heuristic, Adjustment Heuristic, and Anchoring Heuristic were included. The scale had totally 40 items including ten in each sub-dimension. The answers given to the scale were ranked in five-point Likert type as totally inappropriate, partly inappropriate, some appropriate, appropriate and totally appropriate. Internal consistency coefficients related to the sub-dimensions of the scale varied between .58 and .84 . The reliability of the scale that was determined by test-retest method ranked between .58 and .92 when investigated in terms of sub-dimensions.

\subsubsection{Internally Controlled Responsibility-Externally Controlled Responsibility Scale:}

Internally Controlled Responsibility (ICR) -Externally Controlled Responsibility (ECR) scale developed by Özen and Gülaçtı [22] included 18 items. Because ICR and ECR scales were on Likert type, the reliability of all scale and sub-scales was performed through Cronbach Alpha reliability coefficient. At the end of the study, Alpha reliability coefficient for all scale was found as (.67), and the coefficient was found as $=73$ for Internally Controlled Responsibility sub-dimension of the scale, and as $=62$ for Externally Controlled Responsibility sub-dimension of the scale. Obtained reliability coefficients proved that the scale could reliably be used. The validity of ICR and ECR scales were investigated through similar scales' validity method. Locus of Control Scale was given to 342 students beside ICR and ECR scales. The correlation between total scores of both scales and the scores related to the sub-scales were found with "Pearson Correlation Coefficient." The correlation was determined as (.67). Internal consistency and test-retest method were also used for the validity of the test. Internal consistency was found as Alpha $=.94$, and re-test reliability was found as significant at the level of $(\mathrm{r}=.73)$.

\subsubsection{Personal Information Form}

The personal information form developed by the researcher was used to obtain data related to the study group upon some demographical information such as age, gender, and the faculty being studied at.

\subsection{Data Collection}

In order to obtain data in the research, Personal Information Form, Decision Heuristics Scale and Internally Controlled Responsibility (ICR) -Externally Controlled Responsibility (ECR) scales were performed to the students in groups volunteered for participating into the study of the 
researcher in their classrooms. Before employing the data collection tools to the students, they were informed about how measurement tools would be filled in. Employment of measurement tools took nearly 45 minutes.

\section{Findings}

As result of the analyses, average of the scores students took from Internally Controlled Responsibility-Externally Controlled Responsibility scale was found as 9.78, and the standard deviation was found as 3.98. This obtained value proved that the students who participated in the research had internally controlled responsibility. Score averages and standard deviation values the students who participated in the research took from each sub-dimension of the Decision Heuristic Scale, and the correlations of Decision Heuristic Scale with Internally Controlled Responsibility-Externally Controlled Responsibility Scale were presented in Table 2.

Table 2. Averages of the scores high school students took from Decision Strategies Inventory, Correlation of standard deviation values and decision strategies inventory with internally-externally controlled responsible scale

\begin{tabular}{|c|c|c|c|}
\hline Sub-dimensions & $\mathrm{X}$ & $\mathrm{SD}$ & $\mathrm{r}$ \\
\hline Representative heuristic & 35.08 & 6.92 & $-.27^{* *}$ \\
\hline Availability heuristic & 32.88 & 6.01 & $.23^{* *}$ \\
\hline Adjustment heuristic & 28.33 & 5.87 & -.01 \\
\hline Anchoring heuristic & 27.48 & 6.58 & $.26^{* *}$ \\
\hline ICR-ECR & 9.78 & 3.98 & - \\
\hline
\end{tabular}

$* * \mathrm{P}<0.001$

When average values presented in Table 2 were investigated, the students participated in the research were noticed to use representative heuristic most $(X=35.08$; $\mathrm{SD}=6.92)$. They were determined to use availability heuristic $(\mathrm{X}=32.88 ; \mathrm{SD}=6.01)$ and adjustment heuristic $(X=28.33 ; \mathrm{SD}=5.87)$, subsequently. The rate of the ones using anchoring heuristic was found as low $(X=27.48$; $\mathrm{SD}=6.58$ ). When the correlation of decision heuristics with internally controlled responsibility-externally controlled responsibility scale was investigated, a negative and low level relationship was found between representative heuristic and internally controlled responsibility-externally controlled responsibility scale $(\mathrm{r}=-.27 ; \quad \mathrm{p}<.001)$. Whereas no relationship was specified between adjustment heuristic and internally controlled responsibility-externally controlled responsibility scale, the correlation of availability heuristic $(\mathrm{r}=.23 ; \mathrm{p}<.001)$ and anchoring heuristic $(\mathrm{r}=.26 ; \mathrm{p}<.001)$ with internally controlled responsibility-externally controlled responsibility scale was positive and at a low level.

In the research, decision heuristics used by the individuals with internally controlled responsibility and externally controlled responsibility were also compared. Before this comparison, average and standard deviation of Internally Controlled Responsibility-Externally Controlled Responsibility Scale was benefited in order to determine the students with internally controlled responsibility and externally controlled responsibility. The students that had 3.98 standard deviation over the average $(n=170)$ were determined to have externally controlled responsibility, and the students that had 3.98 standard deviation below the average $(n=200)$ were determined to have internally controlled responsibility. Then, whether there was a significant difference according to the decision heuristics the students with internally controlled responsibility and externally controlled responsibility had or not was tried to be determined through t-test.

Table 3. Score Averages, Standard Deviation and T-values High School Students Obtained from Internal-External Locus of Control

\begin{tabular}{|c|c|c|c|c|c|}
\hline Decision Heuristic Scale & \multicolumn{2}{|c|}{ Int. Cont. Resp. } & \multicolumn{2}{|c|}{$\begin{array}{c}\text { Ext. Cont. } \\
\text { Resp. }\end{array}$} & \\
\hline Sub-dimensions & $\mathrm{X}$ & $\mathrm{SS}$ & $\mathrm{X}$ & $\mathrm{SS}$ & $\mathrm{t}$ \\
\hline Representative heuristic & 38.43 & 7.12 & 33.82 & 6.97 & $6.07^{* *}$ \\
\hline Availability heuristic & 28.59 & 6.66 & 32.66 & 5.98 & $5.40^{* *}$ \\
\hline Adjustment heuristic & 32.99 & 7.90 & 32.97 & 6.99 & .40 \\
\hline $\begin{array}{c}\text { Anchoring heuristic } \\
\text { heuristic }\end{array}$ & 25.66 & 7.93 & 29.98 & 5.88 & $5.46^{* *}$ \\
\hline
\end{tabular}

$* * \mathrm{P}<0.001$

When the results presented in Table 3 were investigated, a significant difference was determined between representativeness and availability heuristic of individuals with internally controlled responsibility and externally controlled responsibility and anchoring heuristic. No significant difference was found in representative heuristic use of individuals with internally controlled responsibility and externally controlled responsibility. Representative heuristic use of students with internally controlled responsibility $(X=38.43 ; \quad S D=7.12)$ was found to be significantly higher $(\mathrm{X}=33.82 ; \mathrm{SD}=6.97)$ rather than the representative heuristic use of students with externally controlled responsibility $(\mathrm{t}=6.07 ; \mathrm{p}<.001)$. When availability heuristic was investigated, average of the students with internally controlled responsibility $(X=28.59 ; \mathrm{SD}=6.66)$ was significantly lower $(X=32.66 ; S D=5.98)$ than the average of the students with externally controlled responsibility $(t=5.40 ; p<.001)$. When investigated in terms of anchoring heuristic, averages of the students with internally controlled responsibility $(X=25.66 ; \mathrm{SD}=7.93)$ was determined to be lower $(X=29.98 ; S D=5.88)$ than averages of the students with externally controlled responsibility $(\mathrm{t}=5.46 ; \mathrm{p}<.001)$.

\section{Discussion}

In this study, the students who participated in the research were determined to use representative heuristic most as result of the analyses. Subsequently, the students were noticed to use availability heuristic, adjustment heuristic and anchoring heuristic, respectively. The rate for using anchoring heuristic was low among the students. In the study 
of Brighton and Gigerenzer [7] upon final grade university students and adults, it was determined that university final grade students mostly used representative heuristic, and then adjustment and availability heuristics, respectively; they used anchoring heuristic as the least. This finding was consistent with the results obtained in this study.

Another question that was tried to be answered in the research was whether the university students participated in the research had internally controlled responsibility or externally controlled responsibility. It was determined that the students who participated in the research generally had internally controlled responsibility as result of the statistical data calculation. This result was consistent with the finding obtained in various studies. In the studies carried out upon this subject, it was observed that as the age increased, the individuals had more internally controlled responsibility. For example, in the study carried out by Dawes [23], $11^{\text {th }}$ grade students were noticed to have more internally controlled responsibility rather than the $10^{\text {th }}$ grade students. Dhami [24] also emphasized that individuals used internally controlled responsibility more as time passed.

On the other hand, when the relationship between internally controlled responsibility-externally controlled responsibility and decision heuristics was investigated, low but significant relationship was determined between responsibility control differentiation and representative heuristic, availability heuristic, adjustment heuristic and anchoring heuristic. When direction of the relationship was investigated, a negative relationship was found between internally controlled responsibility-externally controlled responsibility and representative heuristic. This result indicated that as the score taken from the responsibility scale decreased, namely as the individuals had more internally controlled responsibility, the score taken from the representative heuristic increased. On the other hand, a positive relationship was proved between externally controlled responsibility and availability heuristic and anchoring heuristic. In other words, as the score taken from the scale increased, namely as the individuals had more externally controlled responsibility, the score they had from the availability heuristic and anchoring heuristic increased, as well. Although the correlation values obtained in this study were significant and terminal, the correlation was not adequate to make a generalization. Furthermore, as result of the analyses performed in the study, the individuals who had internally controlled responsibility were specified to use representative heuristic more than the ones with externally controlled responsibility. On the other hand, the individuals with externally controlled responsibility were determined to use availability heuristic and anchoring heuristic more. These results proved that the individuals with internally controlled responsibility and externally controlled responsibility used different decision heuristics. This finding obtained in the study was consistent with the findings in the study of Dougherty, Watkins, Thomas [25].

\section{Conclusions}

In this research, obtaining a finding that the individuals with internally controlled responsibility used representative heuristic more emphasized the importance of the fact that the individuals should have internally controlled responsibility in order to make more logical and accurate decisions. This result also revealed the importance of students' having internally controlled responsibility for their post-graduate professional career and academic development, and also the importance of guidance services provided in schools to make students use representative heuristic and adjustment heuristic. In this sense, the teachers carrying on their duties at schools can determine students with externally controlled responsibility specifying the control direction of students' responsibilities, and guidance programs related to them can be administered. So that students are helped to develop accurate and appropriate decision heuristic skills.

\section{REFERENCES}

[1] Astebro T, Elhedhli S. (2006). The effectiveness of simple decision heuristics: forecasting commercial success for early-stage ventures. Manage. Sci. 52:395-409

[2] Rollinson, D. (2002): Organizational Behaviour and Analysis An Integrated Approach (Second Edition): Pearson Education Ltd: Essex

[3] Backlund LG, Bring J, Skaner Y, Strender L-E, Montgomery H. (2009). Improving fast and frugal in relation to regression analysis: test of 3 models for medical decision making. Med. Decis. Making 29:140-48

[4] Ersever, Ö. Hakan. (1996). Karar Verme Becerileri Kazandırma Programının ve Etkileşim Grubu Deneyiminin Üniversite Öğrencilerinin Karar Verme Stilleri Üzerindeki Etkileri. Yayınlanmamış Doktora Tezi. Ankara Üniversitesi Sosyal Bilimler Enstitüsü, Ankara/Türkiye ( Decision Making Skills Program Gaining Experience and Interaction Group of the Impact on Decision Making Styles of University Students. Unpublished PhD Thesis. Ankara University Institute of Social Sciences, Ankara/TURKEY)

[5] Driver, M. J., K. R. Brousseau, P. L. Hunsaker. (1990): The Dynamic Decisionmaker Five Decision Styles for Executive and Business Success. Harper \& Row: New York.

[6] Baucells M, Carrasco JA, Hogarth RM. 2008. Cumulative dominance and heuristic performance in binary multiattribute choice. Oper. Res. 56:1289-304

[7] Brighton H, Gigerenzer G. 2011. How heuristics exploit uncertainty. In Ecological Rationality: Intelligence in the World, ed. PM Todd, G Gigerenzer, ABC Res. Group. New York: Oxford Univ. Press. In press

[8] Tversky A. 1972. Elimination by aspects: a theory of choice. Psychol. Rev. 79:281-99

[9] Tversky A. 1977. Features of similarity. Psychol. Rev. 84:32752 
[10] Tversky A, Kahneman D.1973. Availability: a heuristic for judging frequency and probability. Cogn. Psychol.5:207-32

[11] Lee MD, Loughlin N, Lundberg IB. 2002. Applying one reason decision-making: the prioritization of literature earches. Aust. J. Psychol. 54:137-43

[12] Pachur T, Todd PM, Gigerenzer G, Schooler LJ, Goldstein DG. 2011. When is the recognition heuristic an adaptive tool? In Ecological Rationality: Intelligence in the World, ed. PM Todd, G Gigerenzer, ABC Res. Group. New York: Oxford Univ. Press. In press

[13] Johnson, R. H. (1978). Individual styles of decision making: A theoretical model for counseling. Personal and Guidance Journal, 56, 530-536.

[14] Bergert FB, Nosofsky RM. 2007. A response-time approach to comparing generalized rational and take-the- best models of decision making. J. Exp. Psychol.: Learn. Mem. Cogn. $331: 107-29$

[15] Hanselmann M, Tanner C. 2008. Taboos and conflicts in decision making: sacred values, decision difficulty, and emotions. Judgm. Decis. Mak. 3:51-63

[16] Mann, L., Hormoni, R., ve Rover, C. (1989). Adolescent decision making: the development of competence. Journal of Adolescence, 12, 265-278.

[17] Ferrari, J. R. ve J. F. Dovidio. (2000): Examining Behavioral Processes in Indecision: Decisional Procrastination and Decision-Making Style. Journal of Research in Personality, $34,127-137$

[18] Gardner, D. C ve Warren, S. A. (1978). Careers and Disabilities: A Career Education Approach. Connecticut: Greylock Publishers
[19] Smith L, Gilhooly K. 2006. Regression versus fast and frugal models of decision-making: the case of prescribing for depression. Appl. Cogn. Psychol. 20:265-74

[20] Lee MD, Cummins TDR. 2004. Evidence accumulation in decision making: unifying the "take the best" and the "rational" models. Psychon. Bull. Rev. 11:343-52

[21] Özen, Y. (2015). Karar Heuristikleri Ölçeği. Eğitimde Kullanılan Eğitsel ve Deneysel Ölçekler Kitabı. Yason Yayınları. Ankara/Türkiye (Scale their heuristic decision. The educational and experimental scale Books used in education. Yason Publications. Ankara Turkey).

[22] Özen, Y; Gülaçt1, F (2011). Development of Internally and Externally Controlled Responsibility Scale: Validity, Reliability and Analysis World Applied Sciences Journal 12 (2): 139-144, 2011 ISSN 1818-4952 IDOSI Publications

[23] Dawes RM. 1979. The robust beauty of improper linear models in decision making. Am. Psychol. 34:571-82

[24] Dhami MK. 2003. Psychological models of professional decision making. Psychol. Sci. 14:175-80

[25] Dougherty MR, Franco-Watkins AM, Thomas R. 2008. Psychological plausibility of the theory of probabilistic mental models and the fast and frugal heuristics. Psychol. Rev. 115:199-213

[26] Kahneman, D. 2003. Maps of bounded rationality: a perspective on intuitive judgment and choice. In Les Prix Nobel: The Nobel Prizes 2002, ed. T Frangsmyr, pp. 449-89. Stockholm: Nobel Found. 